\title{
Self-consciousness and intersubjectivity: dimensions of the social self
}

\author{
Katja Crone $^{1}$ • Wolfgang Huemer ${ }^{2}$
}

Published online: 15 November 2017

(C) Springer Science+Business Media B.V., part of Springer Nature 2017

\section{Introduction to the special issue: Investigating the Social Self}

Questions about the nature and the structure of the self and self-consciousness give rise to fundamental problems that have received new attention in contemporary philosophy. The vivid exchange with neighbouring disciplines, especially with psychology and neurophysiology, has brought about a dynamic and innovative debate. The traditional philosophical perspective on the self and self-consciousness with its leaning towards metaphysical, epistemological, and semantic questions has been broadened by an interest in the empirical reality of self-consciousness and its bodily basis. Moreover, the philosophical critique of individualistic positions that traditionally studied the mind detached from a social setting has found an echo in other disciplines, such as in psychology and cognitive neuroscience. It is now broadly accepted that central issues concerning self-consciousness should not be studied by taking into account the individual alone, but also by exploring the role of intersubjectivity and interaction with the social environment.

Such social underpinnings of self-consciousness bear interesting connections to other problems that are currently intensely discussed in philosophy of mind and phenomenology, namely collective intentionality and social cognition. Even though it is agreed that these issues are related to one another in various ways, most discussions focus on only one of them and ignore the other ones. As a result, the interrelations between these fields of study often remain unattended. The contributions in this volume intend to overcome this shortcoming by drawing attention to the interdependence of the three topics and by presenting and discussing new insights and their mutual explanatory value from the perspective of empirically informed philosophy of language and mind as well as phenomenology. In so doing the

Katja Crone

katja.crone@tu-dortmund.de

1 Institut für Philosophie und Politikwissenschaft, Technische Universität Dortmund, Emil-Figge-Str. 50, 44227 Dortmund, Germany

2 Dipartimento di Discipline Umanistiche, Sociali e delle Imprese Culturali (DUSIC), Università degli Studi di Parma, Via D’Azeglio 85/a, 43125 Parma, Italy 
articles explore a number of previously underexposed, yet important connections between different approaches.

The prospect of an integrated view becomes especially apparent when looking at the basic relation between self-consciousness and intersubjectivity. From an ontogenetic perspective, a social environment plays an important role for the development of reflective self-consciousness in individuals. An exploration of the ontogenetic roots of selfconscious thought quickly brings to the fore the interaction with others as an essential condition for the acquisition of this ability. There are different perspectives from which this issue can be approached: phenomenological analyses show that subjectivity and intersubjectivity are inextricably linked to one another (e.g., Husserl 1973; Zahavi 2001) and that social interaction - in various forms - is an important component in the development of awareness of oneself and of others (e.g., Gallagher and Hutto 2008).

Empirical findings in developmental psychology show that this development is intimately connected with our skills of cultural learning and shared intentionality that are rooted in our ability to understand persons as intentional agents, which is present already in one year old children (Tomasello and Rakoczy 2003). Cognitive neuroscientists shed an interesting light on the role of a sensory feedback system for the formation not only of a bodily self, but also for the distinction between self and others (Farmer \& Tsakiris 2012, Tsakiris 2017). Further insights from cognitive science and developmental psychology suggest that self-consciousness develops in correlation with the development of a theory of mind (e.g., Happé 2003). Following Strawson (1959) and Evans (1982) one can finally argue from the perspective of philosophy of language that the ability to ascribe mental states and properties to oneself implies the ability to ascribe these also to others who are not oneself.

The ability to ascribe mental states to others is typically discussed under the headings of "social cognition" or "mindreading". Standard approaches are concerned with the question of what it means to interpret and predict other persons' behaviour by ascribing mental states to them. More precisely, these approaches try to account for our every-day practice of dealing with others as sentient beings who act according to practical reasons. Subject to debate is the question of which underlying structures are in fact responsible for our ability to ascribe mental states to others - whether we apply law-like generalizations (Gopnik and Wellman 1994; Gopnik and Metzloff 1997), or whether we put ourselves into the shoes of the other (e.g., Goldman 1989; Goldman 2006; Currie and Ravenscroft 2002) or whether we form a dynamical system due to interaction and mutual engagement (Fuchs and De Jaegher 2009; De Jaegher et al. 2010). In these discussions, however, it is taken for granted that the ability to perceive others' mental states requires that one is a sentient and self-conscious being oneself who may likewise be the target of this type of ascription by others. It seems, thus, highly profitable to take a closer look at the relationship between the structure of selfconsciousness and the perception of others' mental states. So far, few attempts have been made to analyse this relationship in more detail. Carruthers, for instance, argues that understanding others' behaviour by ascribing mental states to them is the source of selfunderstanding (2009). He claims that self-understanding requires to turn so-called mindreading abilities upon oneself. This implies the assumption that the ability to ascribe mental states to others is prior to the ability to self-ascribe mental states. Goldman (2006), in contrast, holds that the ability to interpret the behaviour of others depends on one's introspective access to one's own mental states. The core claim is that one applies the model of one's own mind to another person to understand what she thinks and feels. This suggests 
that the ability to self-understand is either prior to the ability to understand others or that both are interdependent and run in parallel (Newen 2015). The view seems to get support from neurocognitive research on mirror neurons: findings suggest that we get initial evidence for others' inner lives when our own behavioural tendencies are activated by merely observing others (Gallese et al. 1996). Furthermore, phenomenological approaches such as by Merleau-Ponty and Husserl argue that interacting with others and perceiving them as subjects is rooted in the structure of subjectivity (Zahavi 2001).

The question of how strategies of mindreading may be related to joint attention and group agency has hardly been discussed in the recent debate, though. In what sense does social cognition presuppose forms of collective intentionality - and vice versa? The articles of this volume explore different facets of interrelations between collective intentionality, social cognition and self-consciousness and will thereby hopefully stimulate new discussions in the respective fields of study.

In his article "Subject of "We intend"', Schmid addresses the relationship between self-consciousness and collective intentionality. He is concerned with the question of what is responsible for the collectivity in collective attitudes expressed in sentences of the form "We intend to $\varphi$ " and argues against dominant approaches according to which collective intentions are reducible to, for instance, individual intentions with an appropriate content. According to Schmid, we rather have to conceive of the "we" in collective attitudes in terms of a plural subject which can be characterized in analogy to the singular subject, that is, in terms of (plural) self-consciousness. Schmid spells out how central features of singular self-consciousness also apply to the perspective of a plural subject: for instance, the special way a subject self-refers and self-ascribes certain mental states and attitudes; a commitment related to one's intentions; and a first-person authority. According to Schmid, what explains the collective structure in collective intentions is that they are owned and known by a plural subject.

The interrelation between collective intentionality, social cognition, and social interaction plays an important role in Martens' and Schlicht's article "Individualism versus Interactionism: About Social Understanding". Their argument focuses on recent approaches to social cognition, according to which perceiving and understanding others' mental states presupposes social interaction, that is, a form of joint activity. Against this view the authors argue that any form of joint activity already requires some basic social understanding of each other, which is why the explanation offered by current approaches is circular. Martens and Schlicht then bring forward their own position on how to ground social understanding: drawing on Millikan's notion of most basic representations and on insights from developmental psychology, the authors make a case for a representationalist analysis of the concept of social affordances. Accordingly, interaction-oriented representations offer certain kinds of interaction and can therefore function as a background condition of social cognition.

In her paper "Understanding Others, Reciprocity, and Self-Consciousness", Crone approaches the question of how to ground social cognition and interaction from a different angle, addressing the basic relation between self-consciousness and intersubjectivity. Crone points out that in current interactionist accounts of social cognition the meaning of the core notion 'interaction' remains rather unclear. Turning to the example of social cognition presumed in verbal communication, she argues that the underlying interaction needs to be spelled out in terms of a particular stance persons adopt towards each other. Importantly, this interpersonal stance - termed "dispositional reciprocity" - requires that persons implicitly acknowledge each other as free and self-conscious agents. This brings to the fore the mutual 
dependence of intersubjectivity and self-consciousness. Crone's analysis of this structure is inspired by an argument originally introduced by Fichte and further supported by data from developmental psychology. She suggests that dispositional reciprocity functions as a basic background condition of social cognition.

The question of whether mirror selfrecognition presupposes a self-concept is at the centre of Brandl's contribution "The puzzle of mirror self-recognition".. In the literature, the mirror test has been interpreted very differently and discussed controversially, which indicates that mirror self-recognition is a complex phenomenon that includes different components. Among other things, Brandl argues, it is often overlooked that mirror self-recognition might not be an on-or-off phenomenon; rather, it is plausible to assume that it is the result of a gradual development that involves forms of partial selfrecognition. Brandl relies on Perner's multiple-models theory that explains how children in the second year of their development can acquire the ability to use various different models in representing facts that do not fit into their model of reality and suggests that there is a close tie between mirror self-recognition and the ability to engage in pretend plays. When an infant passes the mirror test for the first time, selfrepresentational abilities might not yet be in play; the child might just pretend (rather than believe) that there is another child in the mirror and recognize that by using her normal skills it can control the duplicate in the mirror. According to Brandl, this skill deserves to be labelled partial self-recognition.

In her article "The personal and the subpersonal in the theory of mind debate", Musholt focuses on the requirements that need to be fulfilled so that an organism can engage in social cognition. According to the received view, these requirements are quite complex as they include the mastery of a common folk psychology and in particular the possession of mental state concepts like belief, desire or knowledge. It therefore has been criticized as phenomenologically implausible and overly complex, since it cannot account for the fact that children successfully engage in social interactions before they possess mental state concepts; moreover, the attribution of mental states is computationally quite demanding and cannot, therefore, provide satisfactory explanation. Musholt argues that an appeal to the distinction between personal and subpersonal processes cannot safeguard the received view from these critiques. She concludes that an alternative, pluralist model that operates on a gradual distinction between nonconceptual and conceptual representations of mental states in others is needed. In particular, she suggests that early infants can have nonconceptual ways of representing mental-statelike states in others and argues that with the acquisition of language, which eventually allows for more complex attributions of mental states, these nonconceptual mental-statelike representations do not disappear, but rather account for the efficiency and automaticity of our mental state ascriptions by adults.

Philosophers who reflect on the social foundation of the self often present Descartes' position as the main target of critique. Descartes argues that one has infallible knowledge concerning one's own occurrent thoughts - and only them. This seems to suggest that one's thoughts are completely independent from the social environment which, after all, could be nothing but a big illusion. This perspective on Descartes has been widely accepted and become an essential part of the mainstream narrative in contemporary philosophy of mind. In contrast to this view, Burri argues in his article "The Cartesian Other" that there are good reasons to assume that Descartes' own position concerning self-knowledge essentially involves the access not only to one's own, but 
also to other minds. Burri offers an interpretation that gives preference to Descartes' epistemology over his metaphysics, questioning principles that are often considered central to Descartes' position and suggests that substance dualism and indirect realism are untenable on Cartesian grounds.

\section{References}

Carruthers, P. (2009). How we know our own minds: The relationship between mindreading and metacognition. Behavioral and Brain Sciences, 32(2), 121-182.

Currie, G., \& Ravenscroft, I. (2002). Recreative minds: Imagination in philosophy and psychology. Oxford: Oxford University Press.

De Jaegher, H., Di Paolo, E., \& Gallagher, S. (2010). Can Social Interaction Can Constitute Social Cognition? Trends in Cognitive Science, 14(10), 441-447.

Evans, G. (1982). Varieties of reference. New York: Oxford University Press.

Farmer, H., \& Tsakiris, M. (2012). The bodily social self: A link between phenomenal and narrative selfhood. Review of Philosophy and Psychology, 3(1), 125-144. https://doi.org/10.1007/s13164-012-0092-5.

Fuchs, T., \& De Jaegher, H. (2009). Enactice Intersubjectivity: Participatory sense-making and mutual incorporation. Phenomenology and the Cognitive Sciences, 8, 465-486.

Gallagher, S. (2008). Direct perception in the intersubjective context. Consciousness and Cognition, 17, 535-543.

Gallagher, S., \& Hutto, D. (2008). Understanding others through primary interaction and narrative practice. In J. Zlatev, T. P. Racine, C. Sinha, \& E. Itkonen (Eds.), The Shared Mind: Perspectives on Intersubjectivity (pp. 17-38). Amsterdam: John Benjamins.

Gallese, V., Fadiga, L., Fogassi, L., \& Rizzolatti, G. (1996). Action recognition in the premotor cortex. Brain, 119(2), 593-609. https://doi.org/10.1093/brain/119.2.593.

Goldman, A. I. (1989). Interpretation psychologized. Mind and Language, 4, 161-185.

Goldman, A. I. (2006). Simulating minds. The philosophy, psychology, and neuroscience of mindreading. Oxford: Oxford University Press.

Gopnik, A. (1993). How we know our minds: The illusion of first-person knowledge of intentionality. Behavioral Brain Sciences, 16, 1-14.

Gopnik, A., \& Metzloff, A. (1997). Words, thoughts, and theories. Cambridge: Bradford MIT Press.

Gopnik, A., \& Wellman, H. M. (1994). The 'Theory-Theory'. In L. Hirschfeld \& S. Gelman (Eds.), Domain specificity in culture and cognition. New York: Cambridge University Press.

Happé, F. (2003). Theory of mind and self. Annals of the New York Academy of Science, 1001, 134-144.

Husserl, E. (1973). Zur Phänomenologie der Intersubjektivität. Texte aus dem Nachlass, Teil I -III (Husserliana 13-15). Den Haag: Martinus Nijhoff.

Newen, Albert A.(2015) Understanding others - The person model theory. In Thomas Metzinger \& Jennifer M. Windt (Eds.), Open MIND: 26 (T). Frankfurt am Main: Mind Group. https://doi.org/10.15502 /9783958570320

Scheler, M. (1954). The nature of sympathy. London: Routledge.

Strawson, P. F. (1959) Individuals: An essay in descriptive metaphysics. London: Methuen.

Tomasello, M., \& Rakoczy, H. (2003). What makes human cognition unique? From individual to shared to collective intentionality. Mind and Language, 18, 121-147.

Toumela, R. (2005). We-intentions revisited. Philosophical Studies, 125, 327-369.

Tsakiris, M. (2017). The multisensory basis of the self: From body to identity to others. The Quarterly Journal of Experimental Psychology, 70(4), 597-609. https://doi.org/10.1080/17470218.2016.1181768.

Zahavi, D. (2001). Beyond empathy. Phenomenological approaches to intersubjectivity. Journal of Consciousness Studies, 8 (5-7), 151-167. 